\title{
Introducción al Ande y su Habitante
}

\author{
(Notas para una estética de la Montaña)
}

TJENE la forma de una tromba. La espira comienza por un rasgo sutil de menudos fragmentos, que se funden hasta lograr el ritmo ascensional de una columna. A mitad de camino se enarcan las caderas, dilátase la pared interior, crecen los hombros. Se diría un cuerpo mutilado, que aventó la cabeza para afirmar el imperio del torso formidable. Este torbellino plástico, envuelve un alma en evasión. Inasible, contradictorio, cruzado de hermetismo, el todo escapa a las definiciones. Cuerpo y alma se sustraen, huyen vertiginosamente como la tromba del centro que la. inicia.

Sudamérica es huraña a la síntesis. Calza todas las medidas sin ajustar ninguna.

Para unos es el espejo que devuelve, reducida, la imagen europea. Para otros la factoría económica de los Esstados Unidos. Del Golfo de México se divisa una tierra de indios. De Buenos Aires la matriz cosmopolita. Cuna de la raza cósmica al decir del pensador, se transforma en continente de la negación y de la muerte para el novelista. Piensa el tropicalismo en cierta reserva cultural de la humanidad. Responden los pragmáticos que ya pasó la hora de estas jóvenes naciones. La tesis del indio inorgánico, halla su réplica en la doctrina del terrícola forjador de sus instrumentos de dominio. Razas "fellahs" - piensan los más. Pueblos concentrados, a la espera - responden los menos. El soñador exclama: iLa América India irradia la magia de una virgen dormida! El sociólogo pregunta: ¿.Es que ella existe verdaderamente? Lo que existe son 
grupos de pueblos, intenciones de trasplantes, hacinamientos que tratan de hacer nación. Somos un mundo en germen.

De un lado, la hipérbole; de otro, rechazo y negaciones. Mas siempre una atracción indefinible gira en el compás del Almirante, desvía la brújula del Vespucio, imanta las agujas de los geógrafos. Magia india. Territorio del instinto y la emoción, que sólo entrega por intuiciones sus fragmentos; jamás su cabalidad.

Nuevo Mundo - claman los antiguos. Pero el moderno empieza a sospechar las remotas vivencias del suelo mítico, anterior al tiempo clásico. Arqueólogos, lingüistas, apenas balbucean la interpretación de nuestro pasado. Un dios bifronte enseña sus caras indescifrables, enigma siempre recomenzado: siendo lo más nuevo, ser siempre lo más viejo. Sin verlas, se siente su presencia. Sin palparlas, se padece su contraste. Donde la razón vacila, golpea el corazón sus adivinaciones. "South America" - murmulla el turista. Fuente sellada, vigencia del misterio - replica el alma india.

La América Meridional va de un medioevo a otro medioevo. Sus renacimientos perecieron sin dejar rastro. Del despotismo oscurantista del Inca, pasa al vasallaje férreo de la Colonia. Falta esa tradición milenaria de hechos históricos, ciencia organizada y técnica evolutiva, telón de fondo de las viejas culturas.

Una centuria de apariencia democrática y esencia caciquil, desenfrenado liberalismo, ideas románticas, economía semicolonial, no arroja saldo muy favorable. Macaquismo, espíritu imitativo dirá el maestro. Careciendo de medida interior para proyectarnos sobre el contorno, somos, en verdad, una cultura potencial. i Tremenda responsabilidad la del sudamericano! Vive cargado de fuerzas; fuerzas que presionan, salen de su órbita y se desgastan en fricciones estériles, rompiendo el equilibrio del medio con el hombre. Habita el orden mágico del desorden. No señorea el mundo; padece de sujeción telúrica. Lentitud y taciturnidad están en ruptura con el disciplinado vértigo moderno. La disparidad étnica conspira contra la unidad política. Sobran tierras. Escasean pobladores. Falta un estilo creador frente a la poderosa actividad del inmigrante. En un sentido ontológico-humanista, no somos, todavía. Estamos en trance de ser.

¿Sudamérica es más del Austro, del Septentrión o de Occidente? 
Vibra un mosaico de pueblos y costumbres. Lo que impera en una región no reza para otra. Hay urbes populosas, atentas a la civilización electro-mecánica. Hay aldeas hundidas por las altas montañas, donde habitan culturas supérstites, ajenas al acontecer contemporáneo. El mestizo sudamericano maneja un motor o absorbe la visión fílmica, mejor que cuanto puede asimilar el espíritu del ancestro. Es apto para la técnica y esquivo al humanismo. Triple heredero del lemur, del atlante y de los mayas, su psique rechaza al europeo en cuanto lo indígena predomina sobre lo español. Aprende sin enseñar. Desprecia a quien superó. Emula sordamente con los que lo aventajan. Pero Sudamérica no es sólo un mestizaje de sangres y almas. No es lo indio, lo mestizo ni lo blanco aisladamente; mas una extraña amalgama de los tres. Si en ciertos parajes el color de la piel y las costumbres dividen a los hombres en compartimentos estancos, los tres mundos conviven en singular simbiosis, trasmutando características específicas. El individuo simple. La colectividad compuesta y densa.

Hay que pensar, con el filósofo, que este activo laboratorio funde los elementos de un nuevo tipo humano. Gérmenes, siempre gérmenes...

Cuando la tierra se traspasa de espiritualidad, brota el milagro infrecuente de una sabiduría sin ciencia: el héroe, el político, el pensador, el artista, calan más hondo que los europeos. Si no alcanzan su técnica depurada, profundizan cosas más entrañables que escapan a la geometría concertada de Occidente. La ausencia de un clima cultural, frustra ricas posibilidades o esfuma la obra humana. Pocos saben que en un sentido integral, Bolívar removió más fuerzas creadoras que Bonaparte; le faltó el escenario para peraltar sus hazañas. Montaña, trópico y llanura devoran al hombre y al suceso, porque la tierra es aún desmedida para el poblador. Mas cuando el hombre del Sud alcanza su expresión, con brusco salto vence los estadios culturales que lo alejan de Europa; entonces se sospecha que el sudamericano es algo más que el mestizo incomprensible de los sociólogos y bastante menos que el ente abisal, de pura teluricidad, del atisbo keyserlingniano.

Confuso embrión que se despedaza y se reconstruye sin cesar, la América Meridional sugiere una nebulosa apenas revelada. Sus 
cuerpos celestes, como la verdad, están hechos de una piedra luminosa: "ni ríen ni lloran, pero alumbran".

Bolivia es punto culminante de la confusión sudamericana. Somos el pueblo que menos sabe de sí.

La escuela romántica, habla de fatalidad. Un designio adverso justifica todos los contrastes. Aislamiento y retraso provendrian de los caprichos de la naturaleza; luego de los errores de los hombres, predeterminados por el sino: tenía que perderse el Litoral Pacífico, la salida al Atlántico por la hoya platense, el Acre, las tierras del Chaco. Cándido miraje. No hay sinos perpetuamente adversos, enfermedades colectivas ni factores naturales insolubles. Otras naciones vencieron mayores obstáculos hasta lograr organizarse. Nuestros problemas no son más grandes que la medida de nuestra capacidad. Litoral, afluencia al Plata, Acre, Chaco y otras zonas se perdieron por ineptitud interna. Cosmos e historia influyen, naturalmente; en último término, Bolivia purga los errores de los bolivianos.

De un lado pesa lo adverso. Disparidad geográfica. Dislocamiento étnico. Territorios sin contacto. Exigua población. Y el mal mayor: falta de unidad espiritual, poca fe, ausencia de un sentido profundo de patria. Necesitamos "crear un carácter nacional" - dice Tamayo. ¡ Hay que osar, hay que perseverar!

De otro, lo positivo. Late aquí algo entrañable, específicamente americano. Matriz creadora de contrastes, Bolivia presupone mitos, raza, arqueología, culturas milenarias, estética del paisaje, claustro físico y tradición social. Cuanto expresa el genio continental por sus raíces antropogeográficas, hunde su fuerte nervadura en el humus fértil de la meseta andina, aunque la realidad geológica contradiga la imagen subjetiva.

Mundo fabuloso, forjado por altísimas montañas, ríos de metal y mitos tan antiguos como el hombre. ¿Cómo describirlo?

Cuatro rasgos dan el perfil. Un millón de kilómetros cuadrados. Tierras altas, medias y bajas con su secuencia climática: frigidez, zona templada, trópicos. Tres millones de habitantes, con predominio de indios y mestizos y minoría blanca. Política y económicamente, la vida nacional gravita sobre la cuarta parte del territorio y un quinto de la población. Quedan más de setecientos mil kilómetros cuadrados por conquistar: grandes llanuras y salares, inmensos bos- 
ques, hoyas fluviales, sierras metaliferas, valles feraces; y más de dos millones de almas subyugadas al concepto nacional sin participar sus excelencias. Plataforma de comunicación continental, apenas cuenta con dos mil kilómetros ferrados. Malos caminos y en escaso número. Sometida al mercado internacional, la república se reduce a proveer de materias al exterior; la menor oscilación en los precios de fuera, afecta toda la vida boliviana. Colonialismo económico: no se produce lo que se consume. Tercer productor mundial de estaño, el país vive artificiosamente de su exportación. Minería industrializada. Agricultura y ganadería sólo como reservas potenciales. Industrias incipientes. Comercio algo más desarrollado. Invertebración política y social. Dispersa en su estructura étnica por la triple confusión del blanco, del indio y del mestizo, he aquí una comunidad que se esfuerza en ser nación.

Es el promontorio de América - exclama Humboldt. Más entusiasta, agrega D'Orbigny: una mesa de plata asentada sobre bases de oro. Es un corcel tresalbo -añade otro viajero-; los tres remos blancos son sus metales, sus ríos y sus llanos; el negro es su pasado legendario, más enigmático cuanto más distante.

Al miraje del XIX, algo más romántico de cuanto se supone en punto a geógrafos y naturalistas, sucede la escuela analítica del $\mathrm{XX}$, dirigida por sociólogos y economistas: no hay nación propiamente dicha, ni enteramente libre, mientras no organiza por sí la explotación de sus riquezas. Ciñéndonos a este criterio, estaríamos todavía muy distantes de la comunidad orgánica moderna.

Veamos cómo piensan dos autorizados investigadores; extraño el uno, el otro de los nuestros.

Para Pedro Jorge Nicolai, Bolivia es un país que no ha crecido orgánicamente. Formación antinatural, participa de las cuencas del Plata y del Amazonas, estando expuesta a la doble codicia de las naciones que controlan ambos estuarios. Riqueza virgen. Etnica y regionalmente agrietada, lucha duramente por la unidad nacional. No ignora Nicolai nuestra potencialidad en materias primas, mas al recordar que un suelo con muy pocos ricos y una gran masa de población pobre, nunca es verdaderamente rico, aconseja tres soluciones: incorporar el indio a la vida nacional, explotar los yungas tropicales, fomentar la inmigración europea. 
Para Jaime Mendoza somos un territorio de contrastes, formado por "elementos geográficos y sociales tan heterogéneos, que no se diría, a primera vista, parte de una misma nacionalidad. E1 trabajo de integración está por hacerse. Poeta al fin y hombre de fe, Mendoza supera los desalientos del sociólogo con la intuición del soñador; y opone a la tesis de la heterogeneidad constitutiva, la doctrina de la nación natural. Así el mestizo andino, nudo centrípeto de lo boliviano, justifica la existencia política, geográfica y económica de nuestro país. como justificará mañana el grupo étnico que nos suceda en la historia.

¿Quién conoce a este pueblo, aislado en el corazón de un continente?

Estudiante, profesional, hombre de Estado, el boliviano ignora su país. Lo prueban las mutilaciones sucesivas de un territorio jamás controlado en su totalidad. Inabarcable a la visión de conjunto, imprecisa en el detalle, la nación se presenta como un nudo de problemas. La tierra boliviana duerme aún su etapa nocturna, ajena casi por entero al análisis matemático y a la síntesis cualitativa de la ciencia. El escritor no alcanza a traducir lo que no terminó de organizar el poblador. ¿Cuál es el escritor específicamente representativo? Todos arbitrarios e incompletos. Tamayo, planta exótica como pensador y como artista, nos expresa mejor en el campo político y en la pugna con el mundo. Tal vez Jaime Mendoza es el menos imperfecto. Pero ninguno ha dado, aún, la representación cabal de lo boliviano. Es la réplica desconcertante de la América sin meridianos a la Europa cuadriculada: alli se desmenuza el milímetro; aquí se esfuman hasta las leguas.

Poco sabemos de cuanto nos circunda. Hombres y cosas duermen un sueño pétreo. En su porción mayor, territorio histórico y territorio geográfico son país ignorado. Padecemos el drama de la confusión interna y la ausencia de proporciones entre suelo y poblador. Ni vara para la estatura ni balanza para el peso. Existimos de un cierto modo hosco y bravio. En el desorden y la indiferencia, tan alejados de la vertebración política como del vínculo social. Abandono y hurañez conforman nuestra psique. La crítica presente no entraña una visión pesimista; es la mira necesaria hacia dentro, para articularnos mejor y superar la proyección exterior. 
Después del Chaco hay un brusco cambio de eje. Nadie está satisfecho en Bolivia. Irrumpe la cordillera por los valles ubérrimos. Hierven los ríos tropicales. Retumba la selva. Los llanos suben a la meseta. Indios, criollos y blancos en tránsito tenaz. Urbe, aldea, campiña, sierra y desierto juegan al contrapunto. El avión alterna con la carreta y el tren con las balsas de totora. Danza el color en la policromía inverosímil de las vestiduras. Salta el grito por la oposición de las hablas. En este pandemonio colectivo, hay un ansioso anhelo de ser. La aparición del socialismo y de su contraconcepto totalitario es, más que un fenómeno de época, la explosión de un estado de espíritu, deseoso de transformaciones.

¿Auscultásteis el corazón de un continente?

Tiempos dionisíacos de un despertar febril. Viene la voz atropellando al viento. La música más fuerte que el oído. Gira el cristal del aire. Disuélvense las formas para recomponerse al instante. No se percibe el horizonte ni el latido de las cosas. Poderoso torbellino aéreo. IInsensata confusión creadora! Entre parciales derrotas, penosas victorias y súbitos renaceres, no se puede medir cómo crece una nación. Comenzó la "gran batalla del hombre y de las cosas". No hay, no puede haber visión de conjunto. Bolivia se "siente", pero no se ve.

Por el suelo andino que la historia divorció del mar, todo alienta en trance de descubrimiento, en plan de organización, a manera de una inmensa reserva natural. Urbe civilizada y paisaje pánico se equilibran, sin que la mecánica de la naturaleza ceda a la técnica del hombre. Pasado y futuro marchan lado a lado. Es la hora grávida de las definiciones.

Concibo mi patria como una unidad telúrica y social. El boliviano es mi punto de partida. El entendimiento colectivo la meta. Marchar de la soledad, la dispersión y el resentimiento, a la concentración y la solidaridad; es el mensaje de la hora. La hurañía del montañés y la indolencia del llanero, fundiéndose en la grave responsabilidad de una conciencia colectiva. Indio y mestizo son tipos de tránsito. ¿El blanco? Ultramestizo. No, existen razas químicamente puras. Del suelo brota "el boliviano". Y esto debe bastarnos.

Bolivia es un enigma mítico. Un caos telúrico. Un conflicto étnico. Un contrasentido económico. Un drama histórico. Una síntesis estética. Origen, suelo, raza, economía, política, cultura se 
resuelven por esta extraña ley: lo heterogéneo y disperso, lo contradictorio y confuso, aspirando a la unidad. País trágico, sustentado por la oposición de sus elementos constituyentes. Complejo, incoherente, desmedido. Pero la voluntad desbasta pueblos, organiza las cosas; y un día, en lengua demonial, la montaña dirá su secreto: por la contradicción a la unidad.

El historiador se aniquila frente al misterioso destino del andícola. No es el orden ascendente de leones, propicio a los pueblos elegidos de Dios. Es la ringlera simbólica de los bloques basálticos, escalonada en una precipitación de cumbres y fieras serranías, hasta parar en la mansedumbre de la llanura inalterable.

De la más alta cina, del esplendor antiguo, a la quietud actual. Marca el tiempo su encadenada sucesión. Tiwanacu, Kollasuyo, Inkario, Audiencia de Charcas, Alto Perú, Bolivia. En el espacio nos redujimos del señorio de un continente, al millón de kilómetros amurallados en el corazón de América. Todo habla de un caer vertical. Decrecer pudo ser nuestro sino. Vencido, empero, el ciclo de los abuelos jeremíacos, la juventud irrumpe con su nueva fe. $Y$ se ama este pueblo trágico, desgarrado en sus entrañas, precisamente por el sino adverso, por sus caídas y derrotas, por sus cruentas luchas interiores, porque sólo el infortunio tempera y dignifica la misión humana. Aunque únicamente se proyecte sobre nosotros la doble sombra angustiosa de un pasado enigmático y de un presente oscuro, de la tiniebla histórica emerge el rayo de luz: medimos la responsabilidad acrecentada de ser bolivianos, porque la ternura de la patria chica es más honda que el orgullo de la patria grande. $\mathrm{Y}$ al encuentro salimos de un destino mejor; que la Providencia nos concedió uno adverso para probarnos en fortaleza y en ansia de durar.

Tierra nocturna, en concentrada espera...

iQué puñado de gérmenes para el continente! Tiwanacu, la piedra más antigua, guarda el tesoro mítico de América. Del esplendor zafíreo del Titicaca brota el Inkario, raza de guerreros y legisladores. La Villa Imperial surge en un torrente de plata; ; vale un Potosí! no es una frase, mas la síntesis de la Colonia. En el siglo XVIII, los criollos altoperuanos perecen en la horca por una idea de patria. Charcas, capital intelectual del hemisferio sur, sopla de sus claustros el terral emancipador. Primero en proclamar la liber- 
tad, el Alto Perú es el último en obtênerla. No siempre afortunada en sus tentativas de evolución, Bolivia es un crisol inquietante de experiencias. Santa Cruz, Linares, Campero, Montes crean un estilo político americano. No importa que el éxito se aleje de nuestras montañas. Ni las tierras desmembradas. $\mathrm{Ni}$ la sangre vertida. Somos la vanguardia, que salva ejércitos a costa de su propio extravio. Sin disciplina, sin fuerza vertebrada, acometemos obras que no se atreven a emprender naciones mejor organizadas; y es el fracaso donde debía ser la victoria. Pero queda, siempre, el mensaje del Ande, poderoso renovador de pueblos, más allá de la victoria o del fracaso. E1 Ande, porción geográfica que mejor expresa lo boliviano, porque dentro de sus límites se concentra la mayor intensidad de nuestra vida histórica y espiritual. El Ande, que es a un tiempo mismo el núcleo de culturas más antiguas y uno de los focos de civilización menos organizados del continente.

Hay tierras como bolas de cristal; giran, giran en perpetua mudanza. La luz se quiebra en ellas siempre diferente. Ubicuas, variables, volteándose sobre invisibles ejes, devuelven imágenes constantemente nuevas. Essconden su esencia. Es la matemática del absurdo: dos más dos da cinco, seis o siete. Ninguna vara ajusta proporciones. Creemos rozar su secreto; y el alma del país se desvanece por un accidente del paisaje o de su historia. Río perdido, nadie sabe dónde reaparecerá.

El alma de ciertos países es cosa de magia.

¿Se concibe simultáneamente acción e inmovilidad; juventud y madurez; dispersión y ensimismamiento? Algo de fuerza eterna. Algo de cosa frágil, quebradiza. Brujería y misticismo. Pasión e indiferencia contrapuestas. Piedra y hombre inalterables; rigor de frío externo, lava por dentro. ¡Contradicción! ¿Y por qué no? Ya lo sentencian los filósofos: la vida es contradicción, pugna de contrarios. He aquí la ruda belleza de nuestro drama nacional.

El Ande es cosa informe, brusca y sorpresiva, que no acaba de terminar la naturaleza ni concluye de entender el hombre.

Si Fausto admira la matematicidad con que la técnica urbana encierra y dinamiza el vikingo civilizado, Wirakocha replica que la montaña, claustro de los cuerpos, es el clima natural que liberta y dilata las almas. Cuando el pensador, estupefacto, comprueba que la tristeza sudamericana entraña más alto valor que el optimismo 
anglosajón o el idealismo occidental, ha dado la tónica contrapuesta de ambos paisajes: en la urbe mecanizada, el hombre transcurre alrededor del universo; en la naturaleza pánica, el astrónomo es el hombre y todo el universo gira en torno a él.

Costa, llanura y valles ignoran la concentración. La sierra, en cambio, se sustrae al vértigo moderno. ¿De dónde volverán las voces esenciales? Acaso no de los litorales ni del trópico, donde el poblador se abandona al dominio del mundo material, sino de la prisión frígida de las altas mesetas, donde obligado por un medio hostil a revertir sobre sí mismo, el hombre jamás deja de tener conciencia de su espíritu, incubando en la soledad y en el silencio las fuerzas decisivas.

Tierra de misterio, el Ande tiene imantación de siglos. ¿Cuándo llegará el nuevo despertar? Es la incógnita mayor del hemisferio sur, aunque ya sospechamos que la montaña inerva juventud, desde el fiero enigma de su senecta permanencia.

Otro día explicaré hasta qué punto el Ande, el pueblo que lo habita y Franz Tamayo son una trinidad indivisible de la simbiosis telúrica, social e individual. Lo haré al "modo fantástico", porque sólo por la ondulación variable de sus líneas, por la concertación de sonidos que percuten libremente, puede musicalizar el oído las voces de un suelo, de un pueblo y de un hombre que carecen todavía de medida.

Férnando Díez de Medina, La Paz, Bolivia. 